\title{
А.А. Бельцер
}

\section{ПОГРАНИЧНЫЕ БАРОНЫ И МИРОВЫЕ СУДЬИ: СЕМЬЯ ДАКР И МАГИСТРАТЫ КАМБЕРЛЕНДА И НОРТУМБЕРЛЕНДА, 1485-1534}

\begin{abstract}
(с) Бельиер Александр Анатольевич - кандидат исторических наук, доцент кафедры всеобщей истории, международных отношений и документоведения, Самарский национальный исследовательский университет имени академика С.П. Королева, 443086, Российская Федерация, г. Самара, Московское шоссе, 34.

E-mail: abelhist@yandex.ru. ORCID: https://orcid.org/0000-0002-3545-4948
\end{abstract}

\begin{abstract}
АННОТАЦИЯ
Статья посвящена исследованию способов влияния аристократа эпохи Тюдоров на работу местного управления. Проблема становления государства раннего нового времени тесно связана с вопросом о переменах в отношениях между центральной властью в лице монарха и его окружения и существующих элит, особенно региональных. Возможность влияния на работу местной администрации традиционно считается одной из важнейших характеристик власти нобилитета позднего Средневековья. В качестве примера выбраны Томас, барон Дакр (Северная ветвь), один из влиятельных пограничных баронов, и его сын и наследник Уильям. Они на протяжении нескольких десятилетий играли ведущую роль в регионе. Графства, граничащие с Шотландией, и современникам, и потомкам представлялись оплотом непокорной знати. Исследование основано на анализе государственных бумаг эпохи первых Тюдоров: переписки, королевских патентов и грамот.

На протяжении нескольких десятков лет Дакры сами входили в число мировых судей пограничных графств. Они активно принимали участие в работе мировой комиссии, предлагали кандидатуры для включения в состав судей. В мировую комиссию Камберленда, где располагались основные владения баронов, входило значительное число их родственников и слуг. В Нортумберленде, где Дакры недавно приобрели владения, им не удалось настолько повлиять на состав магистратов. Если Томас Дакр в качестве стража Средней и Восточной пограничных марок принимал активное участие в работе мировой комиссии не только Камберленда, но и Нортумберленда, то Уильям Дакр сосредоточился исключительно на деятельности в составе магистратов Камберленда. В работе мировых судей Нортумберленда он не принимал столь живого участия.
\end{abstract}

Ключевые слова: мировые судьи, мировая комиссия, местное управление, Дакр, аристократия, Тюдоры, англо-шотландское пограничье.

Цитирование. Бельцер А.А. Пограничные бароны и мировые судьи: семья Дакр и мировые судьи Камберленда и Нортумберленда, 1485-1534 // Вестник Самарского университета. История, педагогика, филология. 2019. Т. 25. № 4. C. 62-66. DOI: http://doi.org/10.18287/2542-0445-201925-4-62-66.

This is an open access article distributed under the Creative Commons Attribution License Which permits unrestricted use, distribution, and reproduction in any medium, provided the original work is properly cited. (CC BY 4.0) 
Бельцер А.А.

Пограничные бароны и мировые судьи: семья Дакр и мировые судьи Камберленда и Нортумберленда, $1485-153463$

DOI: $10.18287 / 2542-0445-2019-25-4-62-66$

Submitted: $19 / \mathrm{X} / 2019$

UDC 94(415).05

Accepted: 17/XI/2019

A.A. Beltser

\title{
BORDER BARONS AND JUSTICES OF PEACE: THE DACRE FAMILY AND MAGISTRATES IN CUMBERLAND AND NORTHUMBERLAND, 1485-1534
}

(C) Beltser Alexander Anatolievich - Candidate of Historical Sciences, associate professor of the Department of World History, International Relations and Documentation, Samara National Research University, 34, Moskovskoye shosse, Samara, 443086, Russian Federation.

E-mail: abelhist@yandex.ru, ORCID https://orcid.org/0000-0002-3545-4948.

\begin{abstract}
The article describes the ways of aristocratic influence on the local government. The problem of the early modern times state formation is closely related to the issue of changes in the relations between the central authority in the person of the monarch and his entourage and existing elites, especially regional ones.

The influence on the local administration work is traditionally considered one of the most important characteristics of the nobility of the late Middle Ages. For example, Thomas, Baron Dacre (Northern Branch), one of the influential border barons, and his son and heir, William, were selected. For several decades, they played a leading role in the region. From the contemporaries and descendants' point of view the shires, bordering Scotland were taken the stronghold of the rebellious nobility. The research is based on the analysis of the first Tudors era state papers: correspondence, royal patents and letters.

For several decades, the Dacres themselves were one of the border shires magistrates. They took an active part in the work of the commission of the peace, proposed candidates for inclusion in the justices of peace. The Cumberland peace commission, where the main possessions of the barons were, included a significant number of their relatives and servants. In Northumberland, where the Dacres recently acquired property, they were not able to influence immensely the composition of the magistrates. While Thomas Dacre, as the Warden of the Middle and East Border Marches, took an active part in the work of the peace commission not only of Cumberland, but also of Northumberland, William Dacre focused exclusively on activities as part of the Cumberland magistrates. In the activities of the justices of Northumberland, he did not take such a lively part.
\end{abstract}

Key words: justices of peace, commission of peace, Dacre, aristocracy, Tudors, anglo-scottish border.

Citation. Beltser A.A. Pogranichnye barony i mirovye sud'i: sem'ya Dakr i mirovye sud'i Kamberlenda $i$ Nortumberlenda, 1485-1534 [Border barons and justices of peace: The Dacre family and magistrates in Cumberland and Northumberland, 1485-1534]. Vestnik Samarskogo universiteta. Istoriia, pedagogika, filologiia [Vestnik of Samara University. History, pedagogics, philology], 2019, Vol. 25, no. 4, pp. 62-66. DOI: http://doi.org/10.18287/2542-0445-2019-25-4-62-66 [in Russian].

\section{Введение}

Проблема становления государства раннего нового времени тесно переплетается с вопросом о трансформации отношений центральной власти и региональных элит. В случае ренессансной монархии речь идет о взаимоотношениях Короны и аристократии. Данная проблема имеет богатую историографическую традицию, но продолжает оставаться предметом весьма острых дискуссий [Scott 2011]. В англо-американской историографии стимулом интереса к истории английской знати стал выход фундаментального труда Л. Стоуна, посвященного английской знати при Тюдорах и Стюартах [Stone 1965]. Л. Стоун считал, что в этот период экономическое и политическое положение нобилитета постепенно приходило в упадок. За последующие десятилетия концепция Стоуна была в значительной мере пересмотрена, появилось множество исследований, посвященных различным сторонам жизни английского нобилитета Тюдоровской эпохи [Coward 1986; Tudor nobility...
1992; Ross 2011]. Дискуссии относительно перемен в политических и социальных позициях знати велись преимущественно на материалах центральных графств Англии. Пограничным регионам в этих спорах уделялось гораздо меньше внимания. Обращаясь к землям Уэльса и Северной Англии, особенно шотландского пограничья, или английских владений в Ирландии исследователи начинали больше спорить об особости или типичности этих регионов, отличии королевской политики в отношении местной знати на этих землях [Beckingsale 1969; James 1986; Ellis 1995; Ellis 2018].

Менее зависимая от центра власть знати традиционно считается одной из характеристик северной Англии в позднем Средневековье и Раннетюдоровскую эпоху. Примером такого господства магнатов в регионе считаются аристократические семьи Камберленда и Нортумберленда, двух графств, граничащих с Шотландией и составляющих основу трех особых районов - Западной, Средней и Восточной марок. Одним из показате- 
лей власти аристократа в регионе служит возможность влиять на персонал и деятельность местной администрации, прежде всего мировой комиссии. Должность мирового судьи к эпохе Тюдоров стала ключевой в системе местного управления. Попробуем рассмотреть, насколько контроль над местными властями был реализован в деятельности представителей одного из могущественных родов баронов Северной Англии, Томаса Дакра, барона Дакра (Северная ветвь) и его сына и наследника Уильяма.

Томас Дакр с 1485 года и на протяжении сорока лет, вплоть до своей кончины в 1525 году, был одной из влиятельнейших фигур в регионе. Генрих VII первоначально сделал Томаса Дакра наместником Западной марки, в 1504 г. доверил ему должность стража все той же Западной марки [Etty 2012, p. 340]. Генрих VIII не только сохранил за бароном этот пост, но и распространил его полномочия и на две другие марки. В 1511 г. Томас, 3-й лорд Дакр, был назначен стражем всех трех марок и оставался на этом посту до весны 1525 года. Весной 1525 года Дакр был смещен, предстал перед судом по ряду обвинений и приговорен к солидному штрафу и вскоре скончался. Его сын и наследник, Уильям, только в 1528 году смог получить пост стража Западной марки шотландского пограничья. Эту должность он занимал до 1534 года, когда был арестован по обвинению в измене и смещен со всех занимаемых постов.

\section{Дакры и персонал мировых комиссий}

Томас, барон Дакр, входил во все мировые комиссии Камберленда с 1487 года и вплоть до своего смещения в 1525 году. В Нортумберленде Дакр был в составе всех мировых комиссий за исключением 1515 года. Насколько активно Дакр принимал участие в работе мировой комиссии, не было ли его членство в ней формальным? Такой вопрос применительно к тюдоровской знати в целом уже ставился в литературе [Stasevich 2015, c. 130]. Судя по сохранившимся документам, барон регулярно проводил заседания мировой комиссии в своих владениях, в частности в замке Морпет, в Нортумберленде. Например, в обвинениях нортумберлендских дворян, выдвинутых против Дакра, говорится о том, что некий Кокс Карлтон был обвинен в преступлениях и вызван на сессию мирового суда в Морпете, однако там барон не позволил предать его правосудию (Articles of Accusation... 1828, p. 31-40). В 1514 году в качестве мирового судьи графства Нортумберленд Дакр писал кардиналу Уолси о преступлениях Хамфри Лайла против приора монастыря Бринкберн [Charlton 1871, p. 44]. Пытался Дакр и влиять на назначение магистратов. В 1521 году он писал, что custos rotulorum в Камберленде мертв, и предлагал назначить на этот пост Уильяма Бьюли или его сына Ричарда (Letters and papers... 1867, № 1225).

Насколько представительным было количество слуг и родственников Дакра в числе миро- вых судей? Первые мировые комиссии Генриха VII в Камберленде демонстрируют отсутствие людей, связанных с бароном. Первый Тюдор сохранил в основном в составе комиссии слуг Ричарда III, разбавив их своими людьми (Calendar... 1970 a, p. 484). Только во второй половине царствования Генрих VII включил в состав магистратов Камберленда последователей Дакра - Хамфри Конингсби, Томаса Беверли, Генри Дентона и Томаса Кервена (Calendar... 1970 b, p. 634) [Etty 2005, p. 116]. В первые комиссии Генриха VIII кроме самого барона Дакра попали его брат Кристофер, Томас Кервен, Хамфри Конингсби, Генри Дентон и Джон и Хью Хаттоны (Letters and papers... 1862, № 717, 1048, 3553, 5506). В число мировых судей Камберленда в ноябре 1520 года вошли Кристофер Дакр, Томас Кервен, Хью Хаттон и Уильям Бьюли, которого год спустя барон будет рекомендовать в custos rotulorum (Letters and papers... 1867, № 1081 (17)). Наконец, в апреле 1524 года в мировую комиссию графства попали Кристофер Дакр, Кристофер Кервен, родственник Дакра, и клиенты барона - Джеффри и Уильям Ланкастеры (Letters and papers... 1875, № 297 (22)) [Ellis 1995, p. 104].

В Нортумберленде после того, как Томас Дакр стал генеральным стражем марок, в состав магистратов графства попали два его брата, Филипп и Кристофер. Сэр Эдвард Ратклифф и Роджер Фенвик, лейтенанты Дакра и выходцы из местного дворянства, также числились в комиссии. К числу слуг Дакра можно отнести еще одного мирового судью - Джона Беднелла (Letters and papers... 1862, № 3553, 5506). В качестве слуги Дакра его в 1518 году указывает канцлер епископа Даремского Уильям Франклин (Letters and papers... 1864, № 4258). В 1515 году в Нортумберленде из числа людей Дакра в мировую комиссию не попал никто (Letters and papers... 1864, № 249).

В мировые комиссии 1525 года, сформированные уже после осуждения барона, ни он, ни его наследник Уильям не попали. В Нортумберленде комиссия полностью была очищена от людей Дакра. В Камберленде сохранили пост мирового судьи Кристофер Дакр и два дворянина, тесно связанные с семьей Дакр, Уильям и Джеффри Ланкастеры (Letters and papers... 1875, № 1610).

После того как Уильям, лорд Дакр, был восстановлен в должности стража Западной марки, его включили в мировую комиссию в Камберленде, где он числился и в декабре 1530 года и декабре 1532 года (Letters and papers... 1875, № 6803; Letters and papers... 1880, № 1694). В феврале 1531 года Уильям Дакр был включен в мировую комиссию Нортумберленда и в следующих списках от марта и декабря 1532 года также упоминался в еe составе (Letters and papers... 1880, № $119,909,1694)$. Число родственников и клиентов барона среди магистратов Нортумберленда ограничивалось дядей лорда Уильяма, Кристофером Дакром. В Камберленде, где позиции Дакра были прочнее, число родственников и слуг среди 
магистратов было большим. В число мировых судей входил дядя барона, сэр Кристофер Дакр, родственники барона лорд Коньерс и Уильям Парр и давние слуги семьи Джеффри и Уильям Ланкастеры (Letters and papers... 1880, № 119, 909, 1694).

Уильям Дакр так же, как и его отец, принимал участие в работе мировой комиссии, но активность его была ограничена исключительно Камберлендом. Весной 1528 года лорд Дакр сообщал Уолси, что организовал сессию мирового суда в Карлайле, где разбирал дела преступников. В этом же письме барон просил издать новый список мировых судей и включить в состав кворума мировой комиссии Камберленда новых магистратов, поскольку его малочисленность мешает проведению сессий (State Papers 1836, р. 492). В другом письме Дакр рассказывал о сессии мирового суда, проведенной 4 апреля 1528 года по его приказу. Она была посвящена разбирательству относительно побега опасного преступника Ричи Грэма. Лорд Уильям не только дал в письме отчет о разбирательстве, но и приложил материалы дела (State Papers 1836, p. 493).

Влияние Уильяма Дакра на работу мировых судей Камберленда проявлялось не только в том, что он мог организовать сессию суда. Если магистраты должны были разбирать дела, связанные с преступлениями слуг Дакра, то барон мог и помешать проведению сессии. Так случилось при разборе дел о нападениях слуг Уильяма, барона Дакра, на людей Генри Клиффорда, графа Камберленда. Граф обвинял Дакра в срыве сессии мировых судей. Дакр приказал шерифу, которым был один из его клиентов, оставаться в Науорте, одной из резиденций барона, и заниматься ее ремонтом и задержал в этом же замке Джеффри Ланкастера, судью из кворума и custos rotulorum. В результате сессия не смогла состояться (Letters and papers... 1875, № 4790).

\section{Заключение}

В результате мы видим, что как Томас, так и Уильям Дакр не только обладали приверженцами в числе магистратов, но и сами лично принимали участие в работе мировой комиссии, пытались повлиять на ее состав. Они могли не только помочь, но и помешать работе мировых судей, когда это было им выгодно. В то же время в Нортумберленде провести своих людей в мировые судьи Томасу Дакру не всегда удавалось. Связано это было, судя по всему, с тем, что в данном графстве он получил владения недавно благодаря выгодному браку и не смог обзавестись достаточным количеством влиятельных приверженцев. Влияние его в большей степени основывалось на занимаемой должности. В Камберленде у Дакра были большие компактные владения, поэтому в числе мировых судей Камберленда всегда было много людей барона.

Как показывает казус Дакров, наибольшего влияния на состав мировой комиссии у магната получалось достигнуть в том случае, когда совпа- дали два условия: наличие обширных земельных владений в графстве и обладание должностями на королевской службе в его пределах. В такой ситуации аристократ имел возможность снизить вероятность появления альтернативного центра влияния и одновременно привлечь на службу авторитетных представителей местного дворянства. В противном случае он вынужден был постоянно бороться за исполнение своих приказов и был подвержен риску вовлечения в тяжбы с местными джентри.

\section{Источники фактического материала}

Articles of Accusation... 1828 - Articles of Accusation preferred against Lord Dacre, Warden of the East and Middle Marches between England and Scotland, by the inhabitants of Northumberland//Hodgson J. History of Northumberland. Newcastle, 1828. Vol. III (i). P. 31-40.

Calendar... 1970 a - Calendar of Patent Rolls. Henry VII. L.: HMSO, 1914: Nendeln: Kraus reprint, 1970. Vol. 1. 1485-1494. 704 p.

Calendar... 1970 b-Calendar of Patent Rolls. Henry VII. L.: HMSO, 1916: Nendeln: Kraus reprint, 1970. Vol. 2. 1495-1509. $908 \mathrm{p}$.

Letters \& papers ... 1862 - Letters \& papers, foreign \& domestic, of the Reign of Henry VIII, preserved in the PRO, the BM \& Elsewhere in England: 21 vols. L.: 1862-1921. Vol. 1. L.: HMS Office. 1862.506 p.

Letters \& papers... 1864 - Letters \& papers, foreign \& domestic, of the Reign of Henry VIII, preserved in the PRO, the BM \& Elsewhere in England: 21 vols. L.: 1862-1921. Vol. 2. L.: HMS Office. 1864. URL: http://www.britishhistory.ac.uk/letters-papers-hen8/vol2 (accessed 11.10.2019).

Letters \& papers... 1867 - Letters \& papers, foreign \& domestic, of the Reign of Henry VIII, preserved in the PRO, the BM \& Elsewhere in England: 21 vols. L.: 1862-1921. Vol. 3. L.: HMS Office. 1867. URL: http:// www.british-history.ac.uk/letters-papers-hen8/vol3 (accessed 11.10.2019).

Letters \& papers... 1875 - Letters \& papers, foreign \& domestic, of the Reign of Henry VIII, preserved in the PRO, the BM \& Elsewhere in England: 21 vols. L.: $1862-$ 1921. Vol. 4. L.: HMS Office. 1875. URL: http://www. british-history.ac.uk/letters-papers-hen8/vol5 (accessed 11.10.2019)

Letters \& papers... 1880 - Letters \& papers, foreign \& domestic, of the Reign of Henry VIII, preserved in the PRO, the BM \& Elsewhere in England: 21 vols. L.: 1862-1921. Vol. 5. L.: HMS Office. 1880. URL: http:// www.british-history.ac.uk/letters-papers-hen8/vol5 (accessed 11.10.2019).

State Papers... 1836 - State Papers Henry VIII: 11 vols. L: 1830-1841. Vol. 4. L.: John Murray, 1836. 716 p.

\section{Библиографический список / References}

Beckingsale 1969 - Beckingsale B. The Characteristics of the Tudor North. Northern History, 1969, Vol. 4, pp. 67-83. DOI: https://doi.org/10.1179/nhi.1969.4.1.67 [in English].

Charlton 1871 - Charlton E. Memorials of North Tynedale and its Four Surnames. Newcastle, 1871, 101 p. Available at: https://archive.org/details/memorialsnortht00chargoog [in English]. 
Coward 1983 - Coward B. The Stanleys, Lords Stanley \& Earls of Derby. 1385-1672. Manchester: Manchester university press, 1983, 252 p. DOI: 10.1017/ S0003581500081105 [in English].

Ellis 1995 - Ellis S.G. Tudor Frontiers and Noble Power: The Making of British State. Oxford: Oxford University Press, 1995, 332 p. [in English].

Ellis 2018 - Ellis S.G. A crisis of lordship: Robert Ogle, Fifth Lord Ogle, and the Rule of Early Tudor Northumberland. Northern History, 55:1, pp. 61-75, DOI: 10.1080/0078172X.2018.1448565 [in English].

Etty 2012 - Etty C. «Noo man indented for the keeping of the Borders»): Royal Administration of the Marches, 1483-1509. In: England and Scotland at War, 1296-1513. Leiden, Brill, 2012, pp. 329-353 [in English].

Etty 2005 - Etty C. Tudor Revolution? Royal Control of the Anglo-Scottish Border, 1483-1530. Unpublished PhD thesis. Durham: Durham University, 2005. Available at: http://etheses.dur.ac.uk/1283 [in English].

Hodgson 1828 - Hodgson J. History of Northumberland. Newcastle, 1828. Vol. III (ii), 557 p. Available at: https://archive.org/details/historyofnortpt202hodguoft [in English].

James 1986 - James M. Society, Politics and Culture. Studies in Early Modern England. Cambridge: Cambridge
University Press, 1986, 485 p. DOI: https://doi.org/10.1017/ CBO9780511560613 [in English].

Ross 2011 - Ross J. John de Vere, Thirteenth Earl of Oxford, 1442-1513. 'The Foremost Man of the Kingdom'. Woodbridge: Boydell press, 2011, 294 p. Available at: https://www.jstor.org/stable/10.7722/j.ctt81hh0 [in English].

Scott $2011-$ Scott $H$. The early modern European nobility and its contested historiographies, c. 1950-1980. In: Contested Spaces of Nobility in Early Modern Europe. Ed. by M. Romaniello and C. Lipp. Aldershot: Ashgate press, 2011, pp. 11-39 [in English].

Stone 1965 - Stone L. Crisis of Aristocracy. 1558-1640. Oxford: Clarendon press, 1965. 841 p. [in English].

Tudor nobility... 1992 - The Tudor nobility. Ed. by G. Bernard. Manchester: Manchester university press, 1992, 312 p. [in English].

Stasevich 2015 - Stasevich V.A. Titulovannaya znat'v sostave mirovykh sudei pri Genrikhe VIII [Titled nobility among the justices of the peace under Henry VIII]. Vestnik $S P b G U$. Ser. 2 [Vestnik of Saint-Petersburg University. History], 2015, Issue 1, pp. 122-131. Available at: http:// vestnik.spbu.ru/html15/s02/s02v1/13.pdf [in Russian] = Стасевич В.А. Титулованная знать в составе мировых судей при Генрихе VIII // Вестник СПбГУ. Сер. 2. 2015. Вып. 1. C. 122-131. URL: http://vestnik.spbu.ru/html15/ s02/s02v1/13.pdf. 